\title{
The impact of COVID-19 lockdown on children and adolescents and possible solutions: a perspective
}

Nomesh Kumar ${ }^{1}$, Kamleshun Ramphul ${ }^{2}$, Stephanie Gonzalez Mejias ${ }^{3}$, Petras Lohana ${ }^{1}$, Renuka Verma ${ }^{4}$, Yogeshwaree Ramphul ${ }^{5}$, Ruhi Sonaye ${ }^{6}$

${ }^{1}$ Department of Medicine, Liaquat University of Medical and Health Sciences, Jamshroo, Pakistan

2Department of Pediatrics, Shanghai Xin Hua Hospital, School of Medicine, Shanghai Jiao Tong University, Shanghai, China

${ }^{3}$ Department of Family Medicine, The University Iberoamericana UNIBE School of Medicine, Santo Domingo, Dominican Republic

${ }^{4}$ Department of Medicine, Guru Gobind Singh Medical College, Punjab, India

${ }^{5}$ Department of Medicine, Sir Seewoosagur Ramgoolam National Hospital, Pamplemousses, Mauritius

${ }^{6}$ Department of Psychiatry, Bharati Vidyapeeth University Medical College and Hospital, Sangli, India

Submitted: 14 March 2021

Accepted: 30 April 2021

Arch Med Sci Atheroscler Dis 2021; 6: e115-e119

DOI: https://doi.org/10.5114/amsad.2021.107811

Copyright (c) 2021 Termedia \& Banach

\section{Introduction}

The ongoing pandemic of coronavirus disease 2019 (COVID-19) keeps infecting and causing more deaths daily [1, 2]. As of March 29 $9^{\text {th }}, 2021$, the world had registered 127,674,594 confirmed cases with 2,793,319 deaths, amongst which 562,292 occurred in the United States alone [3]. Since the virus is contagious and spreads easily, many countries started issuing lockdown orders at the start of the pandemic [4]. People of all age groups experienced drastic changes in their daily lives. The economic well-being of several countries, especially those relying on travels and tourism, global social and political relationships, pedagogical, and educational systems have all been heavily influenced [1, 4, 5].

With ongoing studies, the importance of masks, isolation, social distancing, and lockdowns became more and more evident. However, these measures received a backlash in several societies and countries, as some people believed that it infringed their freedom of choice and their rights. In today's modern era, while all information is now available at our fingertips, misinformation has been spreading easily during this pandemic. The situation was even believed to have been politicized in some countries $[6,7]$. These issues made it harder to properly contain the virus and encourage vaccination, leading to extended periods of lockdown or social isolation. Shen et al. and Singh et al. both hypothesized that this pandemic has several ill effects on our wellbeing, even without being infected. The containment measures adopted throughout several countries caused multiple public places such as schools and malls to close. This led to less human interaction and also to a rise of stress and anxiety in the face of an unknown new pandemic, eventually culminating in helplessness. They also believe that children and adolescents will experience more long-term effects of this pandemic compared to adults, as they are at a very crucial developmental age $[8,9]$.

\author{
Corresponding author: \\ Dr. Ruhi Sonaye \\ Bharati Vidyapeeth \\ University Medical College \\ and Hospital \\ Sangli, India \\ 26, Sangli - Miraj Road \\ Wanalesawadi, \\ Vijaynagar, Sangli \\ Maharashtra 416410 \\ India \\ Phone: +912332212780 \\ E-mail: drruhisonaye@gmail. \\ com
}


We performed this literature analysis using articles from PubMed using keywords such as "COVID-19", "SARS-CoV-2", "mental health", "children", "adolescent", and "lockdown". The sections illustrate some of the most common and severe changes that have occurred to children and adolescents during the last 15 months since the first case was reported.

\section{Effects on the mental health of children and adolescents}

Lockdowns have made children of all ages realize that there is an ongoing change in the world. Several studies have compared the mental health of children and adolescents to adults. Adolescents were less depressed and stressed than adults below the age of 50 , while a similar level was noted between adolescents and adults above 50 [10 14]. Adolescent girls weremore likely to present with depressive or anxietysymptoms, while "no differences in sexes were seen for children of ages 7-11"[14-17]. Zhou et al. and Rios-González et al. noticed that children from urban areas had lower levels of anxiety than those in rural parts $[14,15]$

COVID-19 also had a financial impact that caused more stress on children and adolescents' mental health. Many parents lost their jobs, leading to a strained financial burden on their family [18, 19]. Balachandran et al. also suggested that having the children at home during lockdowns for long periods can come at a price. The increased hours spent watching television or using the internet can predispose them to a risk of "Internet addiction and for cyberbullying" [20, 21]. A 49\% rise in suicide rates among Japanese children and adolescents has been reported during their second wave [22].

\section{The new classrooms}

With national lockdowns in multiple countries persisting for months, most countries adjusted to an online schooling system. Teachers used several platforms such as Zoom and Skype to provide a medium for tutoring students safely in their own homes. Homeschooling led to more responsibilities for the parents to ensure that they followed their coursework. In their study, Dong et al. found that parents tend to view online learning negatively. Parents believe that there is insufficient self-regulation on behalf of the children that could hinder their education via such platforms. They also thought that they lacked the proper time and know-how for such changes, making their experience more challenging [23]. Meanwhile, Zhao et al. reported that " $76 \%$ of their study sample found that homeschooling is an acceptable solution to the current pandemic". Many tutors are doubtful about their students' interest and focus, and overall academic performances via such pedago- logical and educational methods. Other problems included the longer screen time students have to face and the risks to their health and vision[24]. A "myopic shift" was seen in children of ages 6-8 years, while the number of new cases rose 1.4-3 times in 2020 [25].

Zhao et al. further found that parents and tutors expressed higher levels of anxiety during such sessions, and as many as $17.6 \%$ of students in their sample group faced psychological or behavioral troubles [24]. Online platforms reduce the human interaction between children, their tutors, and their friends. Isolation and loneliness can worsen the impact of COVID-19 on the mental health of children and adolescents [26]. Wiguana et al. found a significant association between school closures in Indonesia and emotional and behavioral problems in adolescents such as "conduct behavior, subjective anxiety, and pro-social behavior problems" [27]. Baron et al. raised concerns about whether school closure could be linked to the lower frequency of allegations of child maltreatment reported in Florida. They may also be more vulnerable to domestic violence [28] as maltreatment cases tend to remain unnoticed and therefore unreported if the child is in lockdown, in the abusive house [29]. In some countries, concerns were also raised over whether having access to $\mathrm{Wi}-\mathrm{Fi}$ and a device for online sessions might create an unfair gap for children from lower socio-economic strata.

\section{Effect on eating, lifestyle, and exercise}

Lockdowns caused several changes to lifestyle, eating habits, physical activity, and sleep. In the general population, Di Renzo et al. found that $48.6 \%$ experienced weight gain while in lockdown [30] and a rise in average body mass was also observed among young adults from 21.8 to $22.1 \mathrm{~kg} / \mathrm{m}^{2}$ [31]. Several studies were also carried out to target and understand the changes seen in children and adolescents. Clarke et al. conducted a study involving children aged $3-5$. Their results showed that children were eating more snacks during the lockdown, had less physical activity, and longer screen time. These habits led to changes in their sleep patterns and difficulties in falling asleep [32]. Similar observations were made during the lockdown in Germany, as physical activities decreased and recreation screen time rose [33].

In their analysis of $17,028,111$ people between the ages of 5 and 25, Stavridou et al. confirmed that weight gain among that group was of great concern. They found changes in dietary behaviors and an increase in unhealthy food consumption. They also linked food insecurity with financial issues [34]. Finally, Khan and Moverley Smith even proposed the unhealthy phenomenon associat- 
ed with weight gain from various causes during COVID-19 as "covibesity" [35]. These lifestyle changes will gradually affect the population and countries as their incidence rates for pre-diabetes, diabetes, obesity, hypertension, and several other comorbid conditions will gradually start to spike.

\section{The cardiovascular impact of lockdown on children and adolescents}

An unhealthy diet, sedentary lifestyle, depressed mood, and emotional stress may turn out to be a recipe for a rise in the early onset of cardiovascular diseases among the current pediatric population in a few decades. Children and adolescents' developmental progress should be tracked carefully, even after the pandemic. Several longterm side effects of a prolonged lockdown can start showing up in early adulthood. Obesogenic behaviors, rise in blood pressure, changes in behavior at home and among peers, and unhealthy lifestyle changes which started during the lockdowns are some of the red flags to look out for.

The lockdown has also affected many chronically ill children and adolescents [36]. To protect them against an unnecessary risk of exposure to the virus, several physicians have shifted to an online telemedicine format. However, many details can be missed out during such consultations. Physicians should encourage and educate their patients to track and report any new symptoms. The fear of a hospital visit should also be addressed with the patient. Many hospitals have changed their criteria for hospitalization and limited the number of visitors, which can be a major issue for the pediatric population [37].

\section{Some possible solutions}

As the pandemic is slowly turning into an endemic [38], there are several changes to the daily routine that can help improve the quality of life of children and adolescents during the lockdown [39].

Since many children and adolescents are experiencing a life-changing phase for possibly the first time, parents and their school must provide proper communication with them about the situation. They may have considerable doubts and will need reassurance that this is a temporary period and eventually the situation will improve. It is also vital that parents themselves channel their COVID-19 stress away from the children. With lockdowns and several companies filing for bankruptcy, many households are facing a financial challenge. Proper guidance and help should also be provided to the parents to prevent displacement of any ill feelings or anger towards the children.

Parents should also be encouraging their children to find things that can help them remain busy. With the boom in technology, children and adolescents can easily have play time with their friends while they are safe at home. Proper positive activities such as games or group chats can allow children to have a safe environment to express their sentiments with their peers openly. It is also vital that parents and schools encourage children and adolescents to keep their regular routines. Schools should try to maintain the same timetables for online classes. Parents should also treat the lockdown as an opportunity to spend quality time with their children. Traditional games and activities can help boost their relationship. Parents and their children can share new hobbies such as cooking. The children can also be encouraged to keep a diary to record their experience in a lockdown. This can provide them with a healthy way to channel their thoughts and possibly clarify any anger or sadness that can arise [39].

Teachers should also raise the issue of COVID-19 and lockdown, and they should encourage students to ask questions and talk about their fears. Proper emotional support is vital even after lockdown. The mental and emotional burden of lockdowns can linger for years, and everyone should still be on the lookout for any behavioral changes that may warrant help. All parties involved should also consider the psychological first aid (PFA) guidelines for such cases [40]. Anonymous suicide help hotlines should be easily accessible to children and adolescents. The stigma of suicide and seeking help for mental health should also be discussed. Eye-catching and visually appealing platforms should be used to address this issue. The pandemic should be properly explained to them, and they should also be encouraged to talk about it. Each age group, ethnic and cultural background should be cared for. Religious leaders and school councils can also play an important role to ensure that young people are not hesitant in such situations $[41,42]$.

Some reports have raised doubts about an educational gap that may arise due to different social groups and backgrounds having less access to study materials and online classes [43]. Some countries have sought to remedy this by shifting their online classes to national television networks [23, 43, 44]. This allows more children to have proper access to their regular classes. However, the gap may still prevail among the households with the lowest incomes. The stress of lockdowns and online courses can also be an issue with teachers, who may face a new challenge. Therefore, it is important to properly orient teachers and adjust teaching materials that can bring a more positive learning approach and have proper coordination with parents to ensure that the new techniques are working. Several community volunteers can also be trained so that any students at high risk for abuse can also be mon- 
itored. In considering the use of antidepressants among children and adolescents to deal with the mental distress of lockdown, the risks and benefits should be carefully weighed [8].

There are multiple possible ways to limit the health-based deleterious effects of lockdowns among children and adolescents. Parents need to limit the screen hours for children. They should promote various indoor activities such as dancing and home work-outs. Furthermore, while there may be a restriction on access to all food products, the intake of junk foods should still be properly monitored. Regular follow-ups with pediatricians can also help assess their growth and identify any significant changes in patterns that could be linked with lockdowns. Post-lockdown protocols to transition and encourage a healthier lifestyle should also be planned by their health care providers. Screening for conditions such as pre-diabetes among high-risk patients should also be encouraged. Early detection will help reduce any complications that may arise in adulthood. Finally, new ways of relaxation, such as yoga and meditation, should also be introduced to children and adolescents. These methods can reduce their stress and lower their gain in weight $[45,46]$.

\section{Conclusions}

In an article published in The Lancet, the WHOUNICEF - Lancet Commissioners highlighted that the world after COVID-19 will be a new, challenging one for our children. Several children have been exposed to emotional, mental, and physical stress during this pandemic. They have missed months to years of normal life, skipped their regular growth monitoring, been deprived of preventive care, and been exposed to a less healthy lifestyle during lockdowns [47]. However, all hope is not lost. With proper cooperation between parents, schools, governments, and other parties involved in the welfare of children and adolescents, we can help them build a better future and shape the societies' wellbeing.

\section{Acknowledgments}

Nomesh Kumar and Kamleshun Ramphul contributed equally.

\section{Conflict of interest}

The authors declare no conflict of interest.

\section{References}

1. Ramphul K, Mejias SG. Coronavirus disease: a review of a new threat to public health. Cureus 2020; 12: e7276.

2. Ramphul K, Mejias SG, Ramphul Y. Headache may not be linked with severity of coronavirus disease 2019 (COVID-19). World J Emerg Med 2020; 11: 274.
3. COVID-19 Coronavirus pandemic. 2020; https://www. worldometers.info/coronavirus/. Accessed $16^{\text {th }}$ October, 2020.

4. Kowlessur S, Ori B, Zimmet P, Tuomilehto J, Chitson P, Ramphul Y. Tackling the COVID-19 pandemic in paradise: the Mauritian experience. Lancet Diabetes Endocrinol 2020; 8: 878-9.

5. Centers for Disease Control and Prevention (CDC). Use of quarantine to prevent transmission of severe acute respiratory syndrome--Taiwan, 2003. MMWR Morb Mortal Wkly Rep 2003; 52: 680-3.

6. Carrion-Alvarez D, Tijerina-Salina PX. Fake news in COVID-19: a perspective. Health Promotion Perspectives 2020; 10: 290-1.

7. Hartley K, Vu MK. Fighting fake news in the COVID-19 era: policy insights from an equilibrium model. Policy Sciences 2020; 53: 735-58.

8. Singh S, Roy D, Sinha K, Parveen S, Sharma G, Joshi G. Impact of COVID-19 and lockdown on mental health of children and adolescents: a narrative review with recommendations. Psych Res 2020; 293: 113429.

9. Shen K, Yang Y, Wang T, et al. Diagnosis, treatment, and prevention of 2019 novel coronavirus infection in children: experts' consensus statement. World J Pediatr 2020; 16: 223-31.

10. Wang C, Pan R, Wan X, et al. A longitudinal study on the mental health of general population during the COVID-19 epidemic in China. Brain Behav Immun 2020; 87: 40-8.

11. Wang C, Pan R, Wan X, et al. Immediate psychological responses and associated factors during the initial stage of the 2019 coronavirus disease (COVID-19) epidemic among the general population in China. Int J Environm Res Public Health 2020; 17: 1729.

12. Qiu J, Shen B, Zhao M, Wang Z, Xie B, Xu Y. A nationwide survey of psychological distress among Chinese people in the COVID-19 epidemic: implications and policy recommendations. General Psychiatry 2020; 33: e100213.

13. Ahmed MZ, Ahmed O, Aibao Z, Hanbin S, Siyu L, Ahmad A. Epidemic of COVID-19 in China and associated psychological problems. Asian J Psychiatry 2020; 51: 102092.

14. Marques de Miranda D, da Silva Athanasio B, Sena Oliveira AC, Simoes ESAC. How is COVID-19 pandemic impacting mental health of children and adolescents? Int J Disaster Risk Reduction 2020; 51: 101845.

15. Zhou SJ, Zhang LG, Wang LL, et al. Prevalence and socio-demographic correlates of psychological health problems in Chinese adolescents during the outbreak of COVID-19. Eur Child Adolescent Psychiatry 2020; 29: 749-58.

16. Xie X, Xue Q, Zhou Y, et al. Mental health status among children in home confinement during the coronavirus disease 2019 outbreak in Hubei Province, China. JAMA Pediatr 2020; 174: 898-900.

17. Chen F, Zheng D, Liu J, Gong Y, Guan Z, Lou D. Depression and anxiety among adolescents during COVID-19: a cross-sectional study. Brain Behav Immun 2020; 88: 36-8.

18. Keith-Jennings B, Llobrera J, Dean S. Links of the supplemental nutrition assistance program with food insecurity, poverty, and health: evidence and potential. Am J Public Health 2019; 109: 1636-40.

19. Crayne MP. The traumatic impact of job loss and job search in the aftermath of COVID-19. Psychol Trauma 2020; 12 (S1): S180-2.

20. Balachandran AK, Alagarsamy S, Mehrolia S. Suicide among children during Covid-19 pandemic: an alarming social issue. Asian J Psychiatry 2020; 54: 102420. 
21. McLoughlin LT, Spears BA, Taddeo CM, Hermens DF. Remaining connected in the face of cyberbullying: why social connectedness is important for mental health. Psychology Schools 2019; 56: 945-58.

22. Tanaka T, Okamoto S. Increase in suicide following an initial decline during the COVID-19 pandemic in Japan. Nat Hum Behav 2021; 5: 229-38.

23. Dong C, Cao S, Li H. Young children's online learning during COVID-19 pandemic: Chinese parents' beliefs and attitudes. Child Youth Serv Rev 2020; 118: 105440.

24. Zhao Y, Guo Y, Xiao Y, et al. The effects of online homeschooling on children, parents, and teachers of grades 1-9 during the COVID-19 pandemic. Med Sci Monitor 2020; 26: e925591.

25. Wang J, Li Y, Musch DC, et al. Progression of myopia in school-aged children after COVID-19 home confinement. JAMA Ophthalmol 2021; 193: 293-300.

26. Loades ME, Chatburn E, Higson-Sweeney N, et al. Rapid systematic review: the impact of social isolation and loneliness on the mental health of children and adolescents in the context of COVID-19. J Am Acad Child Adolesc Psychiatry 2020; 59: 1218-39.e1213.

27. Wiguna T, Anindyajati G, Kaligis F, et al. Brief research report on adolescent mental well-being and school closures during the COVID-19 pandemic in Indonesia. Front Psychiatry 2020; 11: 598756.

28. Li Y, Wang Y, Jiang J, et al. Psychological distress among health professional students during the COVID-19 outbreak. Psychol Med 2020: 1-3. doi: 10.1017/ S0033291720001555.

29. Baron EJ, Goldstein EG, Wallace CT. Suffering in silence: How COVID-19 school closures inhibit the reporting of child maltreatment. J Public Econom 2020; 190: 104258.

30. Di Renzo L, Gualtieri P, Pivari F, et al. Eating habits and lifestyle changes during COVID-19 lockdown: an Italian survey. J Transl Med 2020; 18: 229.

31. Jia P, Zhang L, Yu W, et al. Impact of COVID-19 lockdown on activity patterns and weight status among youths in China: the COVID-19 Impact on Lifestyle Change Survey (COINLICS). Int J Obes 2021; 45: 695-9.

32. Clarke J, Kipping R, Chambers S, et al. Impact of COVID-19 restrictions on pre-school children's eating, activity and sleep behaviours: a qualitative study. MedRxiv 2020. doi: https://doi.org/10.1101/2020.12.01.20241612.

33. Schmidt SCE, Anedda B, Burchartz A, et al. Physical activity and screen time of children and adolescents before and during the COVID-19 lockdown in Germany: a natural experiment. Sci Rep 2020; 10: 21780.

34. Stavridou A, Kapsali E, Panagouli E, et al. Obesity in children and adolescents during COVID-19 pandemic. Children 2021; 8: 135.

35. Khan MA, Moverley Smith JE. "Covibesity," a new pandemic. Obes Med 2020; 19: 100282.

36. Ashikkali L, Carroll W, Johnson C. The indirect impact of COVID-19 on child health. Paediatr Child Health 2020; 30: 430-7.

37. Saqib MAN, Siddiqui S, Qasim M, et al. Effect of COVID-19 lockdown on patients with chronic diseases. Diabetes Metabol Syndr 2020; 14: 1621-3.

38. Castro M, Ares S, Cuesta JA, Manrubia S. The turning point and end of an expanding epidemic cannot be precisely forecast. Proc Natl Acad Sci USA 2020; 117: 26190-6.

39. Ravens-Sieberer U, Kaman A, Erhart M, Devine J, Schlack R, Otto C. Impact of the COVID-19 pandemic on quality of life and mental health in children and adolescents in Germany. Eur Child Adolesc Psychiatry 2021: 1-11. doi: 10.1007/s00787-021-01726-5.
40. Birkhead GS, Vermeulen K. Sustainability of psychological first aid training for the disaster response workforce. Am J Public Health 2018; 108 (S5): S381-2.

41. Singh R, Baral KP, Mahato S. An urgent call for measures to fight against increasing suicides during COVID-19 pandemic in Nepal. Asian J Psychiatry 2020; 54: 102259.

42. Czeisler M, Lane RI, Petrosky E, et al. Mental health, substance use, and suicidal ideation during the COVID-19 pandemic - United States, June 24-30, 2020. MMWR Morb Mortal Wkly Rep 2020; 69: 1049-57.

43. Dhawan S. Online learning: a panacea in the time of COVID-19 crisis. J Educ Technol Systems 2020; 49: https://doi.org/10.1177/0047239520934018.

44. COVID-19: Special arrangements for students and motor vehicle owners. 2020; http://www.govmu.org/English/News/Pages/Covid-19-Special-arrangements-forstudents-and-for-motor-vehicle-owners.aspx. Accessed $13^{\text {th }}$ March, 2021.

45. Kaur H, Singh T, Arya YK, Mittal S. Physical fitness and exercise during the COVID-19 pandemic: a qualitative enquiry. Front Psychol 2020; 11: 590172.

46. Ransing R, Pinto da Costa M, Adiukwu F, et al. Yoga for COVID-19 and natural disaster related mental health issues: challenges and perspectives. Asian J Psychiatry 2020; 53: 102386.

47. WHO-UNICEF - Lancet Commissioners. After COVID-19, a future for the world's children? Lancet 2020; 396: 298-300. 